DOSSIÊ

\title{
Educação e democracia: Base Nacional Comum Curricular e novo ensino médio sob a ótica de entidades acadêmicas da área educacional
}

\author{
Marilda de Oliveira Costa \\ Leonardo Almeida da Silval

\section{RESUMO}

Este artigo analisa a formulação, os interesses envolvidos, bem como os objetivos, de duas novas legislações que alteram aspectos significativos da estrutura da educação brasileira, o binômio novo ensino médio e Base Nacional Comum Curricular, no governo Michel Temer (2016-2018). Para tal, foram selecionados os posicionamentos de três entidades representativas da área educacional: a Associação Brasileira de Currículo (ABdC), a Associação Nacional de Pós-Graduação e Pesquisa em Educação (ANPEd) e a Associação Nacional pela Formação dos Profissionais da Educação (Anfope). Por meio do mapeamento de notas e documentos emitidos por essas entidades das áreas da pesquisa educacional, do currículo e da formação de professores, analisamos os pontos que fragilizam o direito à educação, pela análise de três eixos principais: a noção de democracia no contexto do neoliberalismo; o direito à educação e o conhecimento mais amplo da juventude; e medidas que acenam para a privatização da educação.

\section{PALAVRAS-CHAVE}

Base Nacional Comum Curricular; direito à educação; novo ensino médio; privatização.

'Universidade do Estado de Mato Grosso, Cáceres, MT, Brasil. 


\title{
EDUCATION AND DEMOCRACY: BASE NACIONAL COMUM CURRICULAR AND NOVO ENSINO MÉDIO UNDER THE ACADEMIC EDUCATIONAL ENTITIES'S VIEW
}

\begin{abstract}
This article analyzes the formulation and the involved interests, as well as the objectives of two new legislations which modify aspects of the Brazilian education structure: the binomial novo ensino médio-Base Nacional Comum Curricular during the Michel Temer's government (2016-2018). In this way, the position of three representative entities of the educational area were selected: the Brazilian Curriculum Association (ABdC), the National Association of Research and Graduate Studies in Education (ANPEd), and the National Association for the Formation of Education Professionals (Anfope). Through the mapping of notes, newsletters and other documents issued by these three representative entities of the educational area research, curriculum and teacher training, the points that weaken the right to education by the analysis of three main axes were analyzed: democracy in the context of neoliberalism; the right to education and wider knowledge of youth; and the measures which appoint for the privatization of the education.
\end{abstract}

KEYWORDS

Base Nacional Comum Curricular; right to education; novo ensino médio; privatization.

\section{EDUCACIÓN Y DEMOCRACIA: BASE NACIONAL COMUM CURRICULAR Y NOVO ENSINO MÉDIO BAJO EL PUNTO DE VISTA DE ENTIDADES EDUCATIVAS ACADÉMICAS}

\section{RESUMEN}

Este artículo analiza la formulación y los intereses y objetivos de dos nuevas legislaciones que cambian aspectos de la estructura de la educación brasileña: el binomio novo ensino médio-Base Nacional Comum Curricular durante el gobierno Michel Temer (2016-2018). Así, fueran seleccionados los posicionamientos de tres entidades especializadas del área educativa: la Asociación Brasileña de Currículo (ABdC), la Asociación Nacional de Investigación y Postgrado en Educación (ANPEd) y la Asociación Nacional de Formación de los Profesionales de la Educación (Anfope). A través del mapeo de notas, boletines y otros documentos emitidos por estas tres entidades del área de la investigación educativa, del currículo y de la formación de profesores, se analizaron los puntos que fragilizan el derecho a la educación a partir del análisis de tres ejes principales: la democracia en el contexto del neoliberalismo; el derecho a la educación; y medidas que acenten a la privatización de la educación.

PALABRAS CLAVE

Base Nacional Comum Curricular; derecho a la educación; novo ensino médio; privatización. 


\section{INTRODUÇÃO}

Um dos aspectos mais irritantes do movimento de privatização é que eles fingem ser progressistas. Eles não são. Eles são reacionários, e eles têm a história para provar isso. Eles roubaram a palavra "Reforma", para que pudessem fingir que queriam melhorar as escolas, em vez de admitir que querem substituir as escolas públicas por escolas religiosas, escolas particulares, escolas com fins lucrativos, escolas on-line, tudo menos as escolas públicas. Dica: Destruição não é reforma.

(Ravitch, 2017)

O presente artigo aborda o binômio novo ensino médio e Base Nacional Comum Curricular (BNCC) pela óptica e pelo posicionamento de entidades especializadas e representativas da área educacional brasileira. Em caráter de urgência e não sem resistências, o governo federal instituiu o novo ensino médio por meio da Medida Provisória (MP) no 746/2016 (Lei no 13.415/2017), atropelando o Plano Nacional de Educação 2014-2024 e todo o debate acumulado sobre a elaboração de metas e de políticas públicas referentes à educação brasileira. As duas medidas promovem profundas alterações na organização e no currículo do ensino médio brasileiro, entre elas o estreitamento da formação e, não sem motivo, despertou indignação na sociedade e nos meios acadêmico, sindical e estudantil, cujas lutas e resistências vêm se dando na defesa do direito à educação e às diferenças e a uma escola pública com gestão também pública, além de laica, de qualidade social, de responsabilidade do Estado, para todos e todas e contrária à mercantilização e a privatização da educação. Mediante o mapeamento de notas, manifestos, boletins, moções, entre outros documentos emitidos por três dessas entidades reconhecidas nacionalmente e pela representatividade na área da pesquisa educacional, do currículo e da formação de professores, procuramos extrair os pontos frágeis no que tange a três eixos principais abordados neste artigo: a noção de democracia, o direito à educação e o conhecimento mais amplo da juventude, bem como as ameaças que acenam para mecanismos de privatização da educação.

Os acontecimentos que levaram o país ao impeachment de $2016^{1}$ trouxeram consigo consequências para a democracia brasileira e também para a educação enquanto bem público - direito humano básico de todos - e não poderiam promover efeitos mais danosos à escola pública e a seus professores, tal como ocorrido após essa lesiva ruptura institucional e sua agenda regressiva em termos de direitos. Parte importante da literatura especializada já tem percebido e demonstrado que a escola e a "educação tornaram-se um espaço altamente disputado, de condição pública e potencialmente emancipatória, importante para o nosso futuro, mas cujo próprio poder de decisão acerca desses valores é questionado" (Robertson e Verger,

1 O afastamento provisório (em maio) e posteriormente definitivo (em agosto) da presidenta Dilma Rousseff, eleita em 2014 com 54,5 milhões de votos (51,64\% dos votos válidos), levando seu vice, Michel Temer, à presidência. 
2012, p. 299), especialmente por redes de atores individuais e coletivos, públicos e privados, nacionais e internacionais, com fortes interesses de mercado e, por isso, privatistas, na educação pública brasileira (Avelar e Ball, 2019; Valladares, Girardi e Novaes, 2016; Macedo, 2018).

Nesse contexto e sob tal ótica, essas duas medidas paradigmáticas, a Reforma do Ensino Médio (Lei no 13.415/17) e a BNCC, são aqui analisadas. A BNCC da educação infantil e do ensino fundamental foi aprovada em dezembro de 2017. Já a BNCC do ensino médio foi interrompida em razão da Medida Provisória no 746 (a que propôs o novo ensino médio), aprovada abruptamente em 8 de novembro de 2018, no Conselho Nacional de Educação. Portanto, o presente texto focaliza essas duas medidas cujos aspectos principais subsidiaram as análises acerca das rupturas mais significativas com a Lei de Diretrizes e Bases da Educação Nacional (LDB) no 9.394/96 e as políticas curriculares em curso no país desde a década de 1990, pela perspectiva de movimentos científicos e acadêmicos da área educacional, com base na crítica às lógicas liberais e neoliberais e de mercado sobre a sociedade e a área educacional.

\section{A DEMOCRACIA E OS ASPECTOS POLÍTICOS E ECONÔMICOS DO REFORMISMO NEOLIBERAL NO BRASIL}

O liberalismo é a grande concepção político-econômica, mas também normativa e filosófica, que se hegemoniza e organiza instituições e ideias das sociedades, da economia e da política ocidental moderna, pelos desdobramentos que se deram desde o século XVII, sobretudo no mundo anglo-saxão, em que o capitalismo industrial vigoraria inauguralmente alguns séculos depois. Juntamente com outras dimensões - como a consagração e a consolidação de direitos individuais, em detrimento de uma vontade coletiva (Miguel, 2014, p. 22) -, um entre os principais legados dessa corrente na conformação dos países ocidentais modernos é a criação da ideia de mercado apartada da responsabilidade de garantia de parâmetros mínimos, como bens e serviços públicos básicos, fazendo com que estes fossem entendidos como exclusividade do Estado, em uma separação clara entre o público e o privado. Assim, com a expansão e o avanço do capitalismo em seu viés industrial de meados para o fim do século XIX, percebe-se que as possíveis virtudes do mercado se tornaram, ao contrário, grandes propulsoras de convulsões e conflitos sociais, contexto no qual emergiram e se sistematizaram, entre outras, as críticas socialista e trabalhista, e, com isso, buscou-se reavaliar o papel e a capacidade do Estado como agente que pudesse proporcionar um ordenamento social menos conflituoso do que se via à época.

Assim, a sistematização da crítica socialista em âmbito científico e, posteriormente, sua consecução após a Revolução Russa, se não vieram a significar um ordenamento econômico, social e político pós-capitalista, em grande medida fizeram com que o capitalismo baseado em pressupostos liberais perdesse parte de sua força e hegemonia, sobretudo teórica, especialmente no período entreguerras - no qual se destaca a crise do capitalismo liberal de 1929. Portanto, após o término da Segunda Guerra Mundial, em termos sociais, abriu-se um período de avanços em direitos e 
de proteção social, em uma excepcional e efêmera acomodação entre capitalismo e democracia nos países do centro do capitalismo.

Contudo, de meados para o fim da década de 1970 em diante, com a crise do petróleo e a desvalorização de moedas nacionais, com o retorno da inflação em alguns países e com a consequente queda do crescimento econômico, entre outros problemas, emergiu e tornou-se a tônica da economia política a partir de então um célere e generalizado questionamento à sustentabilidade desse pacto que ficou conhecido nos países centrais pelo nome de Estado de bem-estar social. Surgiram enfaticamente um profundo descontentamento e dúvidas em relação aos gastos públicos em termos de políticas sociais, dado o entendimento de que estas é que minariam a capacidade do Estado de manter um ambiente propício aos negócios, já que seria preciso sustentar uma máquina burocrática e administrativa muito grande para continuar prestando os mesmos serviços. Logo, a desestatização e/ou a privatização de setores da economia que estivessem sob controle público, bem como a desregulamentação do setor financeiro da economia, se tornaram dois grandes motes do retorno dos principais pilares do economicismo liberal no centro do capitalismo a partir dos anos 1980, sobretudo com as reformas de Estado levadas a cabo por Ronald Reagan, nos Estados Unidos, e por Margaret Thatcher, na Inglaterra.

O reformismo neoliberal é, portanto, entendido como a diminuição e a restrição das áreas de atuação do Estado, com vistas à alocação das riquezas produzidas por determinado país prioritariamente ao agrado e serviço do rentismo do capital financeiro internacional. Em países em desenvolvimento, o controle inflacionário e o sistema da dívida pública são mais sensivelmente ainda os pilares dessa estrutura galgada pelo neoliberalismo. Desse modo, para além de uma doutrina econômica, o neoliberalismo começou a se tornar também uma força ideológica hegemônica no centro do capitalismo global a partir dos anos 1980 e, de certa forma, imposta e exportada como modelo para as regiões periféricas do capitalismo, fossem esses países recém-redemocratizados como na América do Sul, bem como nações descolonizadas na Ásia e na África, a ponto de muitos dos governantes eleitos sob plataformas social-democratas ou mesmo de esquerda tendo se inclinado, em algum grau, aos pilares da hegemonia da doutrina neoliberal.

No caso do Brasil, a Constituição de 1988 foi feita a partir de 1986 e promulgada em 1988, um ano antes da queda do Muro de Berlim e do crescente questionamento acerca da viabilidade da social democracia no centro do capitalismo. Com isso, houve ao menos um conjunto de intenções relativas ao Estado de bem-estar social elencadas na Constituição, o que the rendeu o adjetivo de cidadã. Apesar da agenda neoliberal levada à frente, principalmente pelos governos de Fernando Henrique Cardoso durante os anos 1990 em diversos setores da economia brasileira, esse pacto de 1988 foi de certo modo e em algumas áreas específicas - como na criação do Sistema Único de Saúde e na universalização do acesso ao ensino fundamental, entre outros exemplos - viabilizado nesse contexto da nova república. Houve ainda, posteriormente, dado o crescimento econômico possibilitado pela alta dos commodities e do petróleo, além de certa vontade política, a vigência de um contraciclo no Brasil, por conta de uma série de políticas de inclusão social, especialmente nos governos Lula e Dilma (2003-2016). 
Assim, o que vemos atualmente é que a baixa capacidade de transformação das estruturas que o modelo de democracia liberal enseja o coloca em uma espiral de deslegitimação. Ou seja, sua proximidade e seu estacionamento ao largo da possibilidade de um regime de exceção - mesmo que sem rupturas políticas ou jurídicas abruptas - tornam-se cada vez mais factíveis, conforme suas estruturas não possam vir a ser transformadas internamente. Isso deslegitima o sistema como um todo, envolvendo os poderes Executivo, Legislativo e até mesmo o Judiciário, e coloca grande parte da cidadania mais interessada nessa reestruturação muitas das vezes mais próxima - ideologicamente e mesmo fazendo uso do processo eleitoral - do recuo dessa democracia a uma excepcionalidade fascista ou protofascista, tal qual o modo como se deu o afastamento de Dilma Rousseff em 2016 e que levou Michel Temer e uma agenda neoliberal, sintetizada no documento intitulado Uma ponte para o futuro (Fundação Ulysses Guimarães e PMDB, 2015), e ao poder do que próxima a noções de democracia e de cidadania mais aprofundadas e comprometidas com a promoção e a efetividade de direitos básicos. Esses direitos têm sido constantemente ameaçados pela estreita noção de uma suposta capacidade criadora e gestora dos pressupostos de mercado quando comparadas ao Estado, o que enseja reformas como as da área educacional, que ora analisamos, e que representam muito mais ameaças do que reconstruções e avanços no que tange à qualidade social da educação e sua garantia enquanto direito, bem como as ameaças que acenam para mecanismos com vistas à privatização da educação. Afinal, uma rede composta de diversos e poderosos atores dos setores público e privado, nacional e internacional, aproveitou para impor tal agenda regressiva, de base conservadora e neoliberal na sociedade brasileira, com reflexos na área educacional, destacando-se a reforma do ensino médio e a BNCC.

\section{O NOVO ENSINO MÉDIO E A BASE NACIONAL COMUM CURRICULAR EM PERSPECTIVA}

O sociólogo português Boaventura de Sousa Santos (2016) aponta que a democracia representativa hegemônica tem sofrido grande desgaste, dado que tem se transformado de um modelo de democracia liberal em democracia neoliberal, tudo isso mesmo sem a revisão total das constituições vigentes, por conta de dois processos convergentes: a prevalência do capital financeiro e a concentração da riqueza, as quais estreitam a participação cidadã e dão poder de veto às elites sobre as expectativas de vida de segmentos cada vez maiores da população. A democracia neoliberal é, assim, a redução do status do político a um ativo econômico. Ou seja, o mercado político de convicções e ideias, que na democracia liberal não tinha preço, passa a tê-lo nesse modelo. Isso faz com que a democracia como gramática social ceda lugar à democracia instrumental, a qual é "tolerada enquanto serve aos interesses de quem tem poder econômico e social para tanto" (Santos, 2016, p. 22).

Esse contexto de retorno e de aprofundamento da gramática neoliberal ou da nova razão do mundo (Dardot e Laval, 2016) no país, possibilitado com a ruptura democrática e a ascensão de Michel Temer à presidência da república, em 2016, reinaugurou uma série de medidas que restringem ou extinguem direitos 
duramente conquistados e parcialmente materializados, bem como reafirma a supremacia do mercado, em detrimento das políticas sociais, na conformação de reformas educacionais em curso, a iniciar-se pelo ensino médio. Sob orientação e supervisão de organismos internacionais, entre eles o Banco Mundial (BM) e o Banco Interamericano de Desenvolvimento (BID), como ocorrera com a reforma do ensino médio no México, o governo brasileiro reorganiza sua nova agenda educacional voltada para atender a uma lógica de mercado, ressuscitando a figura do professor com notório saber e retirando e/ou flexibilizando disciplinas estratégicas, conforme veremos, e também ao substituir a educação pela aprendizagem por competências, o que desqualifica a formação geral e profissional dos mais jovens. Tal qual contextualizamos, as reformas do ensino médio (Lei $\mathrm{n}^{\circ} 13.415 / 17$, que regulamentou o novo ensino médio e a $\mathrm{BNCC}$ ) não estão isoladas de um conjunto alargado de mudanças no papel do Estado, da cidadania democrática e dos direitos sociais perante um neoliberalismo ainda mais avançado que atropelaram políticas educacionais em andamento, com destaque para o Plano Nacional de Educação (em vigência no período 2014-2024), bem como os debates em andamento sobre polêmicas curriculares (Cury, Reis e Zanardi, 2018; Brasil, 2007, 2013, 2014a, 2014b).

Para além das tentativas de reforma do ensino médio em $2013^{2}$ e também, ao mesmo tempo, da recusa de tal reforma por diversos segmentos da área educacional, pode-se considerar que nas deliberações do Fórum Mundial de Educação ocorrido na Coreia do Sul em 2015 se encontram aspectos que orientaram a reforma do ensino médio - Lei no 13.415/17 -, assim como o Movimento pela Base Nacional Comum (MBNC), grupo privado criado em 2013 e atuante na elaboração de políticas educacionais. Esse fórum teve como objetivos gerais promover oportunidades de aprendizagem ao longo da vida para todos em todos os níveis e ainda oferecer percursos de aprendizagem flexiveis e também o reconhecimento, a validação e a certificação de conhecimento, das habilidades e das competências adquiridas por meio tanto da educação formal quanto da informal, tal como presente na referida reforma.

Não sem críticas de parlamentares, da sociedade, de entidades acadêmicas, científicas, sindicais e do segmento estudantil, rebatidas com argumentos frágeis pelo presidente da república Michel Temer e seu ministro da Educação Mendonça Filho, o novo ensino médio prioriza a flexibilização da matriz curricular, a articulação com a educação profissional e a educação integral com apoio financeiro do governo federal, mesmo após aprovação por esse governo do congelamento de gastos primários por 20 anos (educação, saúde, segurança, assistência social etc.) pela Emenda Constitucional no 95/2016.

Resumidamente, as principais alterações promovidas na LDB (Lei ${ }^{\circ}$ 9.394/96) pela reforma do ensino médio são: a ampliação da carga horária anual,

2 Uma proposta de reformar o ensino médio pós-LDB no 9.394/96 tramitou na Câmara dos Deputados, o Projeto de Lei no 6.840/13. Entre as entidades da área educacional, a Associação Nacional pela Formação dos Profissionais da Educação (Anfope) foi uma das que se manifestaram contra o caráter reducionista, excludente e discriminatório de que se revestia tal proposta, perante as necessidades formativas da juventude de nosso país. 
de 800 para 1.400 horas $^{3}$; a inclusão obrigatória pela BNCC referente ao ensino médio de estudos e práticas de educação física, arte, sociologia e filosofia; e a obrigatoriedade do ensino da língua portuguesa e da matemática nos três anos do ensino médio. Os currículos do ensino médio deverão levar em conta a formação integral do aluno, de maneira a adotar um trabalho voltado para a construção de seu projeto de vida e para sua formação nos aspectos físicos, cognitivos e socioemocionais. $\mathrm{O}$ currículo do ensino médio será composto da BNCC e de itinerários formativos, que deverão ser organizados por meio da oferta de diferentes arranjos curriculares, conforme a relevância para o contexto local e a possibilidade dos sistemas de ensino, também consideradas áreas do conhecimento, a saber:

- I - linguagens e suas tecnologias;

- II - matemática e suas tecnologias;

- III - ciências da natureza e suas tecnologias;

- IV - ciências humanas e sociais aplicadas;

- V-formação técnica e profissional (Brasil, 2018).

A substituição da histórica organização curricular disciplinar por itinerários formativos específicos, com ênfase em cinco áreas do conhecimento e sem a obrigatoriedade da área de ciências sociais, atende a funções utilitaristas, como a formação para um possível mercado de trabalho, subsumindo sobretudo a função de formação para a cidadania, prevista em legislações anteriores.

Quanto à oferta do novo ensino médio, o parágrafo $6^{\circ}$ do art. 35 (Brasil, 2017b) estabelece o seguinte: a critério dos sistemas de ensino, a oferta de formação com ênfase técnica e profissional considerará:

- a inclusão de vivências práticas de trabalho no setor produtivo ou em ambientes de simulação, estabelecendo parcerias e fazendo uso, quando aplicável, de instrumentos estabelecidos pela legislação sobre aprendizagem profissional;

- a possibilidade de concessão de certificados intermediários de qualificação para o trabalho, quando a formação for estruturada e organizada em etapas com terminalidade.

O parágrafo $11^{\circ}$, VI, do mesmo artigo prevê que as exigências curriculares do ensino médio poderão ser atendidas por cursos realizados por meio do ensino a distância ou educação presencial mediada por tecnologias, conforme aprovado na Comissão Bicameral da BNCC do Conselho Nacional de Educação. Fica sob responsabilidade das escolas orientar os alunos no processo de escolha de áreas do conhecimento ou de atuação profissional. O Art. $6^{\circ}, \mathrm{IV}$, da reforma institui a figura de profissionais com notório saber, alterando o Art. 61 da LDB no 9.394/96. Por fim, o Art. 13 institui, no âmbito do Ministério da Educação, a Política de Fomento à Implementação de Escolas de Ensino Médio em Tempo Integral (Brasil, 2017b).

3 Devendo os sistemas de ensino oferecer, no prazo máximo de cinco anos, pelo menos mil horas anuais de carga horária, a partir de 2 de março de 2017. 
As alterações no ensino médio apresentam rupturas profundas com a LDB no 9.394/96, destacando-se ainda o currículo com a instituição da BNCC do ensino médio, aprovada no dia 8 de novembro de 2018 no Conselho Nacional de Educação, seguindo o mesmo ritual acelerado para aprovação, sem debate e sem acolhimento de críticas feitas por alguns segmentos da sociedade, como o foi a BNCC da educação infantil e do ensino fundamental, aprovada em dezembro de 2017. Tal contrarreforma curricular é considerada por especialistas (Freitas, 2018b; Macedo, 2018) equivalente ao common core ${ }^{4}$ norte-americano, ou seja, a base curricular dos Estados Unidos, lá financiada pelo bilionário Bill Gates (Ravitch, 2018) e aqui pela Fundação Lemann, mesmo que o Brasil já possuísse uma trajetória de elaboração de políticas curriculares consistente, nela incluindo-se, por exemplo, as Diretrizes Curriculares Nacionais para a Educação Básica (Brasil, 2013) e o documento intitulado Por uma política curricular para a educação básica: contribuição ao debate da base nacional comum a partir do direito à aprendizagem e ao desenvolvimento (Brasil, 2014a).

Breve consulta à legislação educacional brasileira dá conta de que a temática da BNCC não é assunto novo. Prevista na Constituição de 1988 para o ensino fundamental, foi ampliada para o ensino médio com a aprovação do Plano Nacional de Educação, pela Lei no 13.005/2014 (Brasil, 2014b), em consonância com a Lei no 9.394, de 20 de dezembro de 1996 (LDB), que define as Diretrizes e Bases da Educação Nacional.

Nesse contexto e considerando que a educação não é neutra - portanto, um projeto em disputas - a correlação de forças em torno desse projeto se estende a múltiplos espaços, tal como o foi da concepção à elaboração, ou seja, a produção do texto da BNCC. Cabe aqui destacar o protagonismo de duas importantes entidades da sociedade civil no debate acerca da produção da política curricular no país: a Associação Brasileira de Currículo (ABdC) e o MBNC.

Criada em 2012, a ABdC surgiu em um momento de "efervescência das discussões em torno da BNCC, porém não se restringe a ela"; ao contrário, "busca uma perspectiva crítica sobre a temática", tal qual evidenciado com o "incremento da produção e difusão acadêmica sobre o currículo" (Cury, Reis e Zanardi, 2018, p. 8). Parte dessa produção foi mapeada e sistematizada no livro Base Nacional Comum Curricular - dilemas e perspectivas, organizado por Cury, Reis e Zanardi (2018), no qual fica patente a indução de demandas da $\mathrm{ABdC}$ em parcerias com periódicos nacionais para debater a temática. A pouca participação de diversos segmentos do meio educacional e da sociedade nas definições da BNCC foi também observada pelos autores. Eles apontam a dissimulação de tal processo "falsamente democrático quando, na realidade, foi parcial, não acolhendo as críticas e os debates que ocorreram em paralelo a sua elaboração" (Cury, Reis e Zanardi, 2018, p. 8).

Por sua vez, o MBNC atua desde 2013 e apresenta-se como um grupo não governamental de profissionais e pesquisadores da educação que atua para facilitar a construção de uma base de qualidade. Promove debates, produz estudos e pes-

4 Common core pode ser traduzido livremente como núcleo comum. É uma espécie de base nacional comum voltada para um núcleo central de standards em leitura e matemática. Foi montada por envolvimento dos estados americanos e implementada pelo governo federal daquele país por adesão de cada ente federativo em troca de acesso a recursos federais. 
quisas, investiga casos de sucesso em vários países e entrevista alunos e professores, tal como o Seminário Liderando Reformas Educacionais: Fortalecendo o Brasil para o Século 21, realizado no período de 21 a 24 de abril de 2013, em New Haven, Estados Unidos, a convite da Fundação Lemann e da Universidade Yale. Cabe observar, então, quais atores e entidades tiveram suas vozes acolhidas no processo de elaboração da BNCC, para compreender a correlação de forças presente em torno da definição de um projeto de educação para o país da magnitude da BNCC.

Na versão aprovada pelo Conselho Nacional de Educação, por meio da Resolução $\mathrm{CNE} / \mathrm{CP}$ n$^{\circ}$ 2, de 22 de dezembro de 2017 (Brasil,2017a), foi reforçada a lógica de uma aprendizagem com base em competências, com concepção curricular restritiva e fortemente articulada à avaliação de tipo padronizada e estandardizada. Abandonaram-se o caráter progressista e participativo e a própria concepção de base expressos na primeira e na segunda versão, pois "em cada objetivo de aprendizagem foram apontadas potencialidades de desenvolvimento de temas integradores (também denominados no próprio documento como 'temas especiais')"(Valladares, Girardi e Novaes, 2016, p. 11).

A BNCC do ensino médio, tais como a da educação infantil e a do ensino fundamental, aprovada em 2017, tem problemas de legitimidade, pois não foi fruto de debate coletivo ou de consulta a entidades especializadas, do mesmo modo como ocorreu a reforma do ensino médio, que foi originada de uma MP aprovada a toque de caixa, atropelando esforços e desconhecendo totalmente diversos segmentos da sociedade brasileira interessados na temática, como fica evidenciado pela fala contraditória do ministro da Educação à época, Mendonça Filho, que assim se expressou sobre a elaboração da BNCC: "A BNCC é um documento plural e contemporâneo, resultado de um trabalho coletivo inspirado nas mais avançadas experiências do mundo" (Brasil, 2018, p. 5). Em primeiro lugar, o documento foi elaborado por especialistas. Segundo, não é novidade que a BNCC tem como referência políticas curriculares avaliadas negativamente por pesquisadores da área da educação de países como Estados Unidos, Austrália, Chile e Reino Unido, por serem relevantes indutores da privatização da educação, conforme mencionamos.

O documento do ensino médio, elaborado pelo Ministério da Educação e entregue ao Conselho Nacional de Educação para aprovação, apresenta as características do novo ensino médio com itinerários formativos, disciplinas diluídas em áreas do conhecimento, habilidades socioemocionais, entre outros, cuja formação deve assegurar o desenvolvimento de dez competências gerais, articuladas à "construção de conhecimentos, no desenvolvimento de habilidades e na formação de atitudes e valores" (Brasil, 2018, p. 9). Na BNCC, "competência é definida como a mobilização de conhecimentos (conceitos e procedimentos), habilidades (práticas, cognitivas e socioemocionais), atitudes e valores para resolver demandas complexas da vida cotidiana, do pleno exercício da cidadania e do mundo do trabalho"(Brasil, 2018, p. 8). Essas dez competências gerais da educação básica são apresentadas e podem ser conferidas no documento da BNCC (Brasil, 2018, p. 9-10).

Diversos especialistas, entidades científicas, acadêmicas e sindicais da área educacional debruçaram-se sobre o texto da BNCC e apresentaram críticas e análises muito ricas sobre o conteúdo da proposta, destacando: o estreitamento curricular ao defini-lo 
por habilidades e competências; as possibilidades de negócios para o setor privado com a indústria das avaliações, consultorias, formação contínua de professores; os 20 a $30 \%$ do currículo que pode vir a ser ofertado a distância e que pode ser compreendido no contexto de novos modelos educativos, "uma das principais áreas da política educativa financiada pelo Banco Mundial e BID”(IEAL,2018,p. 41) para a educação na América Latina e no Caribe, abrindo-se, portanto, possibilidades de mercantilização; material didático estruturado, vendido ao setor público por agentes privados; programas de gestão online; entre muitos outros, conforme analisamos em seguida.

\section{POSIÇÃO DE ENTIDADES ACADÊMICAS DA ÁREA EDUCACIONAL SOBRE A REFORMA DO ENSINO MÉDIO E A BNCC}

As propostas de alteração do ensino médio no Brasil por meio da $\mathrm{MP} \mathrm{n}^{\circ}$ $746 / 2016$ e da política curricular BNCC, cujo encaminhamento inicial remonta ao ano de 2013 (Macedo, 2018), têm despertado mobilizações e análises com emissão de notas, artigos, pareceres, manifestos, moções e recomendações de inúmeros sujeitos individuais e coletivos. Entre eles, encontram-se entidades acadêmicas, científicas e sindicais da área educacional, de caráter local, regional e nacional. Para efeitos deste texto e dada a relevância do tema, selecionamos cinco documentos emitidos por entidades com importante representação nacional em três áreas mais específicas: currículo, pesquisa acadêmica na área de educação e formação de professores. São elas: ABdC, Associação Nacional de Pós-Graduação e Pesquisa em Educação (ANPEd) e Associação Nacional pela Formação dos Profissionais da Educação (Anfope), sendo três relacionados à reforma do ensino médio e dois à $\mathrm{BNCC}$, já que selecionamos uma nota conjunta da ANPEd e da ABdC.

A ABdC, criada em 2012, foi escolhida em razão da profícua atuação na promoção do debate acadêmico sobre currículo e na articulação com veículos de socialização dessa produção, bem como pelo seu ativismo em defesa da educação pública, diversa, plural, entre outras demandas de uma escola e educação democráticas. Já o critério de escolha da ANPEd se deu em função de sua relevância no campo da pesquisa e pós-graduação no Brasil e por contar com $4.601^{5}$ associados e mais de 41 anos de existência. Essa entidade tem se posicionado atentamente ao reformismo desenfreado após o impeachment de 2016 e diligente na emissão de notas, moções, manifestos, dossiês, pareceres, entre outros, posicionando-se contrária a cada medida privatista do governo Temer (2016-2018), especialmente do Ministério da Educação, do Conselho Nacional de Educação e do Fórum Nacional de Educação. Por fim, a escolha da Anfope ocorreu pela sua atuação, desde sua criação, em 1980, na luta pela defesa de políticas de formação e valorização profissional que assegurem o reconhecimento social do magistério, seu profissionalismo e profissionalização (Anfope, 2019).

5 LITIMAN, C. Solicitação do número de associados [mensagem pessoal]. Mensagem recebida por marilda.costa@unemat.br, em 2 de agosto de 2019. 


\section{NOVO ENSINO MÉDIO}

Abordamos primeiramente a posição das entidades sobre a reforma do ensino médio ${ }^{6}$, destacando-se quatro eixos de análise que emergiram da leitura dos textos: elaboração de políticas públicas por MP; formação de professores e profissionais com notório saber, flexibilização curricular; e reforma e privatização da educação. Um dos elementos da reforma, a escola de tempo integral, contudo, não será tratada nos limites deste texto.

Quanto ao processo de elaboração e de instituição da política pública por meio de uma MP, as entidades foram unânimes em suas manifestações, como segue:

Em primeiro lugar, é preciso, sobretudo, criticar a forma autoritária como tal política foi instituída, por meio de Medida Provisória, desconsiderando tanto as práticas razoavelmente estabelecidas de debate público quanto desrespeitando instâncias de representação da sociedade civil. Nem mesmo o processo de consulta pública — bastante limitado - foi respeitado como possível instrumento de construção conjunta de políticas públicas. (ABdC e ANPEd, 2016)

A ação do governo Temer com a Emenda à Constituição - PEC 241 - que estabelece o congelamento dos gastos sociais por 20 anos está articulada ao envio de Medida Provisória No 746, de 22 de setembro de 2016 ao Congresso Nacional, alterando o Ensino Médio unilateralmente e sem diálogo com a sociedade. [...] O uso de uma MP para tratar de uma temática importante no âmbito educacional emite o claro sinal de que se trata de um governo avesso ao diálogo. O uso de MP apesar de ser previsto na lei deve ser excepcional. A que interesses obscuros serve uma reforma feita de maneira autoritária e que atropela processos de discussão em curso na Câmara dos Deputados? (ANPEd, 2016)

A ANFOPE - Associação Nacional pela Formação dos Profissionais da Educação - vem a público manifestar-se contra a Medida Provisória no. 746, de 22 de setembro de 2016, que, a pretexto de instituir uma política de fomento a implementação de escolas de Ensino Médio em tempo integral, desorganiza esse nível de ensino, ignorando as discussões anteriores e aquelas em andamento no Brasil sobre os rumos da educação, constituindo grave ameaça a qualidade do Ensino Médio e a formação da juventude brasileira. (Anfope, 2016)

Apesar de tratar-se de medida recente, o debate e as duras críticas ao novo ensino médio elaboradas por especialistas de diferentes áreas do conhecimento, entre eles Freitas (2016), Frigotto (2016), Cury e Reis e Zanardi (2018), têm se avolumado e apontado as fragilidades e debilidades da reforma, conduzida de forma autoritária, por MP, sem a participação de importantes segmentos sociais diretamente interessados no debate, tais como os pais, professores, estudantes e gestores

6 As manifestações referem-se à MP no 746/2016. 
governamentais dos estados e do Distrito Federal, os quais são os responsáveis diretos pela manutenção e pelo desenvolvimento dessa etapa da educação básica. Não sem resistência desses segmentos, a reforma parece interessar diretamente a certos atores e setores da economia como bancos e organismos internacionais, como o Banco Mundial, a Organização para a Cooperação e Desenvolvimento Econômico (OCDE), entre outros. Reformas criam demandas. Atender a elas, no entanto, é a mais nova forma de o capital avançar na definição do conteúdo da educação, na disputa por fundos públicos e, portanto, pela privatização dessa etapa do ensino.

Sobre formação de professores e profissional com notório saber, as entidades manifestam-se contrárias a esse aspecto da reforma:

Em linhas gerais a MP 746/2016 é um documento que pode ser caracterizado como um retrocesso para as políticas educacionais brasileiras para a formação de professores. [...] É questionável também a menção aos "profissionais com notório saber", uma vez que há lacunas no texto quanto ao processo de certificação: haverá ou não possibilidade de reconhecimento dos espaços de formação já existentes no país? Há diferentes possibilidades de significar um "profissional de notório saber" e cabe o questionamento quanto à formação/certificação desse profissional, mesmo que venha a se tratar apenas do docente da formação profissional. (ABdC e ANPEd, 2016, p. 6-7)

A ANFOPE repudia o ataque frontal empreendido a formação e a valorização dos profissionais da educação, uma vez que a MP, ao instituir a contratação de pessoas sem formação específica para o exercício da docência, sem concurso público de provas e títulos, desde que tenham alegado "notório saber", reforça a desqualificação e a desprofissionalização dos professores, com impactos negativos na qualidade do ensino aviltando, sobretudo, a formação, a carreira e os salários do magistério. (Anfope, 2016)

A posição da ANPEd sobre o profissional de notório saber encontra-se no fragmento do eixo flexibilização curricular, por aparecer de forma complementar à posição da entidade sobre o currículo.

O ressurgimento da figura do profissional de notório saber constitui-se clara e inequivocamente como uma afronta aos esforços que o país, os pesquisadores e a produção acadêmica na área de formação de professores e as universidades públicas brasileiras têm despendido na qualificação inicial e continuada dos profissionais da educação de diferentes áreas do conhecimento, considerados fundamentais a uma escola e à educação de qualidade socialmente referenciada. A instituição do profissional de notório saber rompe com um importante ciclo de lutas pela valorização docente no Brasil, tendo na formação inicial e continuada por área do conhecimento um de seus pilares, assim como a Lei no 11.738/08, do Piso Nacional Profissional Salarial. O profissional de notório saber parece estar em consonância com a flexibilização e desregulamentação das relações de trabalho que emergem com a reforma trabalhista (Lei no 13.467, de 13 de julho de 2017), ou seja, com a retirada de direitos dos trabalhadores constituídos historicamente nas lutas sociais. 
Quanto à flexibilização curricular via itinerários formativos, as entidades expressaram o seguinte:

A proposta desta reforma é que os alunos tenham a liberdade de escolher, dentre as disciplinas compreendidas como optativas, as que sejam de seu interesse para a composição de sua grade horária de estudos. Entretanto, na prática, não há flexibilização quando são reduzidas as opções, pois só é necessário que a rede ofereça poucas opções. [...] A ideia de organização dos currículos por itinerários formativos específicos, com ênfases em cinco áreas distintas e sem a área de Ciências Sociais, tende a conferir ao currículo um caráter utilitarista, voltado unicamente ao atendimento de perspectivas futuras de inserção no mercado de trabalho, negligenciando, também, a função de "formação para a cidadania" prevista na LDB. (ABdC e ANPEd, 2016, p. 3-4)

Temos uma gama imensa de pesquisadores que já se manifestaram contra o esvaziamento que a proposta representa para uma educação de qualidade e criticaram a retomada de antigas perspectivas elitistas de separação da formação humana segundo origens sociais dos estudantes. Exemplos disso são a extinção da obrigatoriedade das disciplinas de sociologia, filosofia, artes e educação física do currículo, além da possibilidade que qualquer profissional não licenciado possa exercer o magistério. (ANPEd, 2016, p. 2)

A fragmentação do ensino médio em "itinerários formativos específicos” fere o direito ao conhecimento para a ampla maioria dos estudantes que se encontra no Ensino Médio público, tendo como falsa justificativa um currículo mais flexível e atraente para o aluno, que vá reduzir as taxas de evasão. Isso, de fato, vai aprofundar a dualidade do Ensino Médio e o apartheid social dos jovens pobres, negando-lhes a oferta desse nível em igualdade de condições, favorecendo ainda mais a mercantilização do ensino. (Anfope, 2016)

A nota da ABdC e do Grupo de Trabalho 12 Currículo da ANPEd (2016) é rica em detalhes sobre a reforma do ensino médio, analisada de maneira aprofundada, em oito pontos no documento Posicionamento sobre a Medida Provisória 746/2016 sobre o ensino médio. O documento aborda diferentes aspectos da reforma, com ênfase nas alterações curriculares e na flexibilização imposta com itinerários formativos e áreas do conhecimento, em detrimento da longa trajetória disciplinar na formação do jovem. A nota da Anfope (2016), apesar de não apresentar o tema com tantos detalhes, é também esclarecedora, posicionando-se firmemente contra as alterações/o estreitamento curricular proposto com a MP 746, que retira disciplinas importantes como Artes, Educação Física, Filosofia e Sociologia, negando o conhecimento geral e comprometendo, portanto, a formação política, cidadã, emancipatória da juventude. Em uma palavra, a flexibilização curricular, sem possibilidade de escolhas, é uma artimanha dos reformadores para estreitar a formação da juventude e possibilitar os standards e a criação de mercados no ensino médio.

Quanto aos atores da elaboração da reforma e privatização da educação, as três entidades expressaram visões parecidas: 
A referida MP, mais do que uma proposta curricular, visa a instituir uma $\mathrm{Po}_{-}$ lítica de Fomento à implementação de Escolas de Ensino Médio em Tempo Integral e de regulamentação do [Fundo de Manutenção e Desenvolvimento da Educação Básica e de Valorização dos Profissionais da Educação] Fundeb. $\mathrm{Na}$ prática cria condições para o financiamento público de escolas privadas. No Art. $5^{\circ}$ não há qualquer distinção ou especificação da natureza das escolas que serão contempladas com o repasse dos recursos, abrindo assim a possibilidade de uma nova relação entre o público e o privado "desde que cumpridos os critérios de elegibilidade estabelecidos nesta Medida Provisória [...]" (Art. $6^{\circ}$ ). (ABdC e ANPEd, 2016, grifo do original)

A MP fragiliza o princípio do Ensino Médio como direito de todo cidadão a uma formação plena para a cidadania e o trabalho, abre canais para a mercantilização da escola pública [...]. É possível encontrar na MP claros sinais de propostas de reformadores educacionais e defensores da fragmentação do Ensino Médio e do estabelecimento de canais para parcerias público-privadas. (ANPEd, 2016)

A MP desconsidera as Diretrizes Curriculares Nacionais para o Ensino Médio (Resolução CNE/SEB 2/2012), ignora ainda o Pacto Nacional pelo Ensino Médio e o Plano Nacional de Educação, demonstrando falta de conhecimento da realidade concreta das escolas brasileiras e dos estudantes de nível médio, configurando-se como uma ameaça a educação básica publica, estatal, gratuita e de qualidade social. (Anfope, 2016)

Como assevera Ravitch (2017) sobre a captura do termo reformas por grupos privatistas, ele é utilizado com a aparente intenção de promover supostas melhorias na educação e um dos argumentos é a busca da qualidade, indispensável ao desenvolvimento nacional e à competitividade internacional. Esse discurso escamoteia a real intenção dos reformadores: por um lado, utilizam o discurso da qualidade, quando na realidade a reforma busca atender a um incerto mercado de trabalho; $\mathrm{e}$, por outro, novas redes da educação global e organismos internacionais ${ }^{7}$ induzem países a adotarem políticas globais de educação com interesse na privatização da escola pública, como mostram estudos de Ball (2014), Ball e Olmedo (2013), Freitas (2018a) e o relatório Tendências em Educação, publicado pelo Observatório Latino-americano de Políticas Educativas (Olpe) e pela Internacional de la Educación para América Latina (IEAL, 2018) e como ficou evidenciado na reforma do ensino médio ${ }^{8}$.

7 Banco Mundial, BID e OCDE.

8 O Seminário Desafios Curriculares do Ensino Médio: Flexibilização e Implementação, realizado nos dias 21 e 22 de junho de 2017, promovido pelo Unibanco com ampla participação de diversos sujeitos, incluindo-se aqueles provenientes de organismos internacionais como a OCDE, o Banco Mundial e o BID, pode ser um exemplo de atuação dessas redes, assim como de poderosos atores internacionais. 


\section{BNCC E SEUS DESDOBRAMENTOS NO ENSINO MÉDIO PÚBLICO}

Desde a apresentação da primeira versão da $\mathrm{BNCC}$ até a aprovação da terceira, em dezembro de 2017, e a tramitação e aprovação no dia 8 de novembro de 2018 no Conselho Nacional de Educação do documento do ensino médio separado das demais etapas da educação básica, houve inúmeras manifestações contrárias à proposta de contrarreforma curricular dessa etapa de ensino, bem como de seus desdobramentos e implicações para a formação da juventude brasileira, a formação de professores e os sinais do interesse de novas redes privatistas, perceptíveis desde a gênese da BNCC. Abordamos primeiramente a posição das entidades sobre a contrarreforma curricular, destacando-se três eixos de análise que emergiram da leitura dos textos: processo de elaboração da contrarreforma curricular, currículo e diversidade brasileira, e BNCC e privatização da educação pública.

Quanto ao processo de elaboração, discussão e aprovação da BNCC, ou seja, quanto à sua legitimidade, as entidades também se posicionaram veementemente contrárias à maneira autoritária presente desde a formação de agenda, elaboração e aprovação dessa política curricular:

A Associação Nacional de Pós-Graduação e Pesquisa em Educação/ANPEd e a Associação Brasileira de Currículo/ABdC manifestam-se contrariamente ao documento orientador de políticas para Educação Básica/Ensino Médio apresentado pela [Secretaria de Educação Básica/Ministério da Educação] SEB/ MEC a esse egrégio conselho como Base Nacional Comum Curricular do Ensino Médio. Nossa posição é sustentada no entendimento de que a proposta atenta contra o direito constitucional dos estudantes e da sociedade à educação e à formação cidadã, além de apresentar problemas intrínsecos ao texto, sua intencionalidade e suas possibilidades de execução. [...] Quem tornou público o debate foi o [Conselho Nacional de Educação] CNE e por isso podemos afirmar que a atual BNCC para o Ensino Médio é uma versão piorada, reducionista e autoritária de uma BNCC que já vinha sofrendo inúmeras críticas, em virtude da concepção formalista e conteudista de Currículo. (ANPEd e ABdC, 2018, p. 1 , grifo do original)

A Associação Nacional pela Formação dos Profissionais da Educação, saúda as entidades militantes, professores e estudantes que cotidianamente lutam para construir uma educação verdadeiramente de qualidade, e em especial, aos que estão presentes na Audiência Pública da Região Centro-Oeste sobre a Base Nacional Comum Curricular do Ensino Médio do Conselho Nacional de Educação, manifesta sua posição contrária a BNCC do Ensino Médio e solicita sua retirada da pauta do CNE, e em unidade conjunto das entidades acadêmicas e sindicais, requer a imediata revogação da Lei 13.415/2017, que dispõe sobre a Reforma do Ensino Médio. (Anfope, 2018, p. 1, grifos do original)

O caráter antidemocrático que acompanhou a elaboração e discussão do documento da BNCC foi denunciado em 4 de dezembro de 2017, por meio da carta emitida por seis entidades de caráter nacional, incluindo-se as três abordadas neste 
texto, ao presidente da Comissão Bicameral da BNCC do Conselho Nacional de Educação ${ }^{9}$. As entidades solicitam resposta sobre as notas públicas encaminhadas como contribuições fundamentadas e circunstanciadas sobre a terceira versão da BNCC, por ocasião das diversas audiências públicas realizadas em cada região do país, entre julho e setembro do corrente ano:

Essas entidades representam segmentos importantes de educadores/as e de pesquisadores/as no campo da educação, que apresentam expectativas de verem consideradas as suas análises e propostas sobre a BNCC, salvaguardando o direito de opinar sobre as diretrizes da educação nacional e reivindicar o debate democrático como princípio de construção dos currículos escolares. [...] Visando contribuir com uma concepção curricular inclusiva, plural e emancipatória, que contribua para a garantia do direito à educação pública, gratuita, laica, democrática, inclusiva e de qualidade socialmente referenciada. (Carta das Entidades..., 2017).

A carta conjunta das entidades chama a atenção para características predominantemente antidemocráticas presentes na elaboração de políticas públicas educacionais no Brasil. Algumas exceções a esse modo de atuação foram momentos pontuais, como à época da redemocratização do país na década de 1980, a qual se agregou uma luta também por uma educação democrática e que culminou com a aprovação da Constituição Federal de 1988, e também as discussões que antecederam a aprovação de duas outras políticas públicas de relevância para a área educacional do país, que foram os debates anteriores à aprovação da LDB no 9.394/96 e à elaboração do Plano Nacional de Educação 2014-2024.

O caráter antidemocrático do binômio BNCC e novo ensino médio não foi notado somente no processo de formação de agenda, elaboração, debates e aprovação no $\mathrm{CNE}$, mas nas características de um currículo etnocêntrico, eurocêntrico e reducionista, padronizado para um país heterogêneo, plural e cujas diversidades são sua marca central, como expressaram as entidades:

Do ponto de vista dos seus problemas intrínsecos, a Base Nacional Comum Curricular ao apresentar uma tendência eurocêntrica na compreensão dos conhecimentos e culturas compromete a dimensão democrática da educação na medida em que não faz jus à diversidade territorial, cultural, social e humana brasileira, que deve se expressar nas propostas curriculares, uma vez que não se pode formar cidadãos de um país heterogêneo e plural como o Brasil com conteúdos padronizados e únicos para todas as pessoas. [...] Somos, portanto, contra a ideia de uma proposta curricular pautada em uma base conteudista e

9 Após presidir a referida comissão, o presidente pediu sua saída por meio de carta, de 29 de junho de 2018, por discordar frontalmente da BNCC do ensino médio, pedindo até mesmo a revogação da Lei no 13.405/2017 (reforma do ensino médio). Mais informações disponíveis em: https://avaliacaoeducacional.files.wordpress.com/2018/06/ carta-aos-conselheiros-do-cne.pdf. Acesso em: 20 nov. 2018. 
disciplinarista como é a BNCC-EM, que ignora a pluralidade do mundo, das escolas e de seus sujeitos, adotando modelo que, já sabemos, está fadado ao fracasso. (ANPEd e ABdC, 2018, p. 1)

Acreditamos que a complexidade de uma política curricular nacional não permite a adoção de matrizes curriculares homogeneizadas a ponto de ameaçar o princípio federativo republicano da autonomia dos sistemas estaduais e municipais de ensino e a construção dos projetos político-pedagógicos das instituições escolares, como explicitado nas Diretrizes Curriculares Nacionais da Educação Básica, nas Diretrizes Curriculares para o Ensino Médio e nas Diretrizes Curriculares Nacionais de Formação Inicial e Continuada de Profissionais do Magistério. (Anfope, 2018, p. 1)

A nota conjunta da ANPEd/ABdC expressa uma preocupação recorrente nos meios acadêmicos, sindicais, estudantis e segmentos progressistas da sociedade brasileira, com a aprovação da reforma do ensino médio e a recente aprovação da BNCC do ensino médio no Conselho Nacional de Educação no tocante à formação cidadã. Ao desobrigar Estado e escolas com a área das ciências sociais, fundamental à formação dos educandos para o respeito às diferenças/à pluralidade, à luta por direitos humanos e por transformação social, a nota considera a BNCC um golpe na educação voltada a essa finalidade. A proposta, segundo as entidades, "reforça preconceitos e práticas discriminatórias de caráter machista, racista, homofóbico, misógino, entre outras calcadas em preconceitos diversos, abrindo caminho para práticas de violência e exclusão social, comprometendo, portanto, a promoção da igualdade social" (ANPEd e ABdC, 2018, p. 2).

\section{CONSIDERAÇÕES FINAIS}

Este artigo buscou mapear, compreender e analisar, à luz de referenciais teórico-críticos, a posição de importantes entidades nacionais, representativas da área educacional, no contexto de austeridade e ajustes fiscais, de avanços do neoliberalismo e do conservadorismo no Brasil e na área educacional com a ruptura política de 2016. Desde então, o país vem passando por uma avalanche de medidas e/ou contrarreformas, especialmente no campo da educação, contrariando o ordenamento jurídico para a área, pactuado na Constituição Federal de 1988, na LDB no 9.394/96 e em diversas legislações e políticas públicas instituídas em períodos de efervescência democrática, tais quais foram a Assembleia Constituinte em 1986 e a elaboração do Plano Nacional de Educação 2014-2024. Desse modo, focalizamos o posicionamento crítico de entidades na luta pelo direito à educação pública, com gestão pública, de qualidade social referenciada e democrática e que possuem postura crítica no que se refere aos processos de privatização e mercantilização da educação e à luta pelo respeito à diversidade e à pluralidade da população e das regiões brasileiras contra um suposto novo ensino médio e uma nova base curricular completamente desvinculados dessa nossa realidade, voltados para o afunilamento da formação da juventude e para atender a interesses de elites e entidades políticas e 
sobretudo econômicas, nacionais e internacionais. Assim, conforme demonstramos, o papel do Estado brasileiro na referida reforma remete-nos ao que Boaventura Santos discutiu sobre o papel do Estado nação modernos:

Os Estados-nação têm tradicionalmente desempenhado um papel algo ambíguo. Enquanto, externamente, têm sido os arautos da diversidade cultural, da autenticidade da cultura nacional, internamente, têm promovido a homogeneização e a uniformidade, esmagando a rica variedade de culturas locais existentes no território nacional, através do poder da polícia, do direito, do sistema educacional ou dos meios de comunicação social, e na maior parte das vezes por todos eles em conjunto. (Santos, 2001 apud Afonso e Ramos, 2007, p. 81)

As contrarreformas em curso são preocupantes: por um lado, por conta dos constantes ataques à escola pública promovidos por grupos e redes do mercado educacional global, cujo interesse principal é apropriar-se dos fundos públicos destinados à educação; e, por outro lado, pelos constantes ataques à escola pública e a seus professores patrocinados por movimentos políticos de caráter extremamente conservador e/ou reacionários, de extrema direita, como atualmente o Escola sem Partido, mesmo sem estar legalmente instituído.

Não por acaso, um dos atores principais na articulação da BNCC é a Fundação Lemann, braço social de empresas de um dos homens mais ricos do país, Jorge Paulo Lemann. Por isso, questiona-se: quais são os interesses de uma fundação ligada a um bilionário que atua em diversos setores, como o de bebidas, de empreender esforços na formulação de políticas públicas educacionais para a educação básica? Breve leitura dos documentos e de análises já realizadas por especialistas da área educacional, conforme demonstramos ao longo do artigo, também não deixam dúvidas quanto aos interesses privatistas desses grupos:

Como já vimos verificando em estudos e debates nacionais e internacionais, as políticas de uniformização/centralização curricular + testagem larga escala + responsabilização de professores e gestores traduzido na BNCC/EM funciona como uma tríade orientada para os valores do mercado e tem gerado como consequências: a desvalorização e desqualificação dos sistemas públicos de ensino e seus atores em diversas dimensões, abrindo portas para a privatização, sob a forma de uso privado de recursos públicos ou outras e hordas de demissões com a ampla concentração por grandes empresas na rede privada. (ANPEd e $\mathrm{ABdC}$, 2018, p. 4-5, grifos do original)

A Base Nacional Comum Curricular do Ensino Médio, constitui um grave retrocesso à educação, favorecendo a precarização da formação das juventudes brasileiras, processos de privatização e empresariamento da oferta pública de Ensino Médio, aprofundando as desigualdades educacionais e sociais, ameaçando a democratização do ensino público e distanciando a juventude do direito inalienável à educação com qualidade social, consolidando o processo de apartheid social dos mais pobres. [...] induzindo a oferta a distância, mais uma 
estratégia de mercantilização da educação básica. Esta BNCC representa a prevalência de uma concepção esvaziada e reduzida de currículo, e ao privilegiar as posições defendidas por setores do empresariado interessados na padronização do ensino, desvela-se o real interesse de atender fins mercadológicos, como a venda de material didático e a oferta de serviços de consultoria para a implementação da BNCC, além da venda de pacotes de formação continuada, em um processo que desvia recursos públicos para empresas e fundações privadas, agora elevados, com o aval do MEC, a parceiros preferencias das redes de ensino, em detrimento das Universidades públicas. (Anfope, 2018, p. 2-3)

Já não é novidade que a contrarreforma do ensino médio e do currículo por meio da BNCC atende a interesses outros que não das juventudes e de suas diversidades, sobretudo daquelas provenientes das camadas de maior vulnerabilidade social e que mais necessitam de uma educação pública, gratuita e de qualidade científica, pedagógica e democrática. Para muitos jovens, a escola é o único espaço de socialização, de convívio com culturas outras, com conhecimento mais elaborado e com as possibilidades de relacionar-se com as diferenças, e tais reformas, conforme nos esforçamos em demonstrar, caminham no sentido de precarizar o direito à educação, em vez de garantir sua efetivação e sua ampliação.

\section{REFERÊNCIAS}

AFONSO, A.J.; RAMOS, E. L.-V. Estado-nação, educação e cidadanias em transição. Revista Portuguesa de Educação, Braga, v. 20, n. 1, p. 77-98, 2007.

ASSOCIAÇÃO BRASILEIRA DE CURRÍCULO (ABDC); ASSOCIAÇÃO NACIONAL DE PÓS-GRADUAÇÃO E PESQUISA EM EDUCAÇÃO (ANPED). Posicionamento sobre a Medida Provisória 746/2016 sobre o ensino médio. Disponível em: http://pibid.ufsc.br/files/2016/10/nota_abdc_mp746.pdf. Acesso em: 20 nov. 2018.

ASSOCIAÇÃO NACIONAL DE PÓS-GRADUAÇÃO E PESQUISA EM EDUCAÇẪO (ANPED). Nota pública da ANPEd sobre a Medida Provisória do Ensino Médio MP do Ensino Médio - Autoritária na forma e equivocada em conteúdo. Rio de Janeiro: ANPEd, 23 set. 2016. Disponível em: http://www.anped.org. $\mathrm{br} /$ news/nota-publica-da-anped-sobre-medida-provisoria-do-ensino-medio. Acesso em: 21 nov. 2018.

ASSOCIAÇÃO NACIONAL DE PÓS-GRADUAÇÃO E PESQUISA EM EDUCAÇẪO (ANPED); ASSOCIAÇÃO BRASILEIRA DE CURRÍCULO (ABDC). Exposição de Motivos: BNCC-EM. Disponível em: http://www.anped. org.br/sites/default/files/images/anped_abdc_contrabncc-emago2018final.pdf. Acesso em: 21 nov. 2018.

ASSOCIAÇÃO NACIONAL PELA FORMAÇÃO DOS PROFISSIONAIS DA EDUCAÇẪO (ANFOPE). Manifesto contraa Medida Provisória n 746/2016. Goiânia, 12 out. 2016. Disponível em: http://www.anfope.org.br/wp-content/uploads/2018/05/ Manifesto-Anfope-MP-746-12.10.2016R.pdf. Acesso em: 21 nov. 2018. 
ASSOCIAÇÃO NACIONAL PELA FORMAÇÃO DOS PROFISSIONAIS DA EDUCAÇÃ̃O (ANFOPE). Manifesta sua posição contrária a BNCC do Ensino Médio. Brasília: Anfope, 14 set. 2018. Disponível em: http://www.anfope.org.br/wpcontent/uploads/2018/11/Nota-Anfope-BNCC-EM-2018-Brasilia-14setembro.pdf. Acesso em: 20 nov. 2018.

ASSOCIAÇÃO NACIONAL PELA FORMAÇÃO DOS PROFISSIONAIS DA EDUCAÇẪO (ANFOPE). Apresentação. Anfope. Disponível em: http://www.anfope. org.br/apresentacao/. Acesso em: 27 fev. 2019.

AVELAR, M.; BALL, S. J. Mapping new philanthropy and the heterarchical state: The Mobilization for the National Learning Standards in Brazil. International Journal of Educational Development, v. 64, p. 65-73, 2019. https://doi.org/10.1016/j. ijedudev.2017.09.007

BALL, S. J. Educação Global S.A. Novas redes políticas e o imaginário neoliberal. Tradução de Janete Bridon. Ponta Grossa: UEPG, 2014.

BALL, S.J.; OLMEDO, A.A nova filantropia, o capitalismo social e as redes de políticas globais em educação. In: PERONI, V. M. V. (org.). Redefinições das fronteiras entre o ppúblico e o privado: implicações para a democratização da educação. Brasília: Líber Livro, 2013. p. 33-47.

BRASIL. Ministério da Educação. Educação profissional técnica de nível médio integrada ao ensino médio. Documento Base. Brasília: Ministério da Educação, 2007. Disponível em: http://portal.mec.gov.br/setec/arquivos/pdf/documento_base. pdf. Acesso em: 20 nov. 2018.

BRASIL. Ministério da Educação. Secretaria de Educação Básica. Secretaria de Educação Continuada, Alfabetização, Diversidade e Inclusão. Diretrizes Curriculares Nacionais para a Educação Básica. Brasília: MEC, SEB, DICEI, 2013. Disponível em: http:// portal.mec.gov.br/index.php?option=com_docman\&view=download\&alias=15548-dc-n-educacao-basica-nova-pdf\&Itemid=30192. Acesso em: 20 nov. 2018.

BRASIL. Ministério da Educação. Por uma política curricular para a educação básica: contribuição ao debate da base nacional comum a partir do direito à aprendizagem e ao desenvolvimento. Versão Preliminar. Brasília: Ministério da Educação, 2014a. Disponível em: https://ipfer.com.br/gper/wp-content/uploads/sites/2/2017/12/Governo-FederalDiretrizes-Aprendizagem.pdf. Acesso em: 20 nov. 2018.

BRASIL. Plano Nacional de Educação. Lei no 13.005, de 25 de junho de 2014. Brasília, 2014b. Disponível em: https://www2.camara.leg.br/legin/fed/lei/2014/lei13005-25-junho-2014-778970-publicacaooriginal-144468-pl.html. Acesso em: 18 de novembro de 2018.

BRASIL. Conselho Nacional de Educação. Resolução CNE/CP no 2, de 22 de dezembro de 2017. Institui e orienta a implantação da Base Nacional Comum Curricular, a ser respeitada obrigatoriamente ao longo das etapas e respectivas modalidades no âmbito da Educação Básica. Brasília: CNE, 2017a.

BRASIL. Novo Ensino Médio, Lei no 13.415, de 16 de fevereiro de 2017. Brasil, 2017b. Disponível em: http://www.planalto.gov.br/ccivil_03/_Ato2015-2018/2017/ Lei/L13415.htm. Acesso em: 22 nov. 2018. 
BRASIL. Base Nacional Comum Curricular. Educação é a Base. Ensino Médio. Brasília: Ministério da Educação, 2018.

CARTA DAS ENTIDADES AO PRESIDENTE DA COMISSÃO DA BNCC DO CONSELHO NACIONAL DE EDUCAÇÃO. 2017. Disponível em: http://www.anped.org.br/sites/default/files/images/oficio_cne_04.12.17.pdf. Acesso em: 20 nov. 2018.

CURY, C. R. J.; REIS, M.; ZANARDI, T. A. C. Base Nacional Comum Curricular - dilemas e perspectivas. São Paulo: Cortez, 2018.

DARDOT, P.; LAVAL, C. A Nova Razão do Mundo. Ensaio sobre a sociedade neoliberal. Tradução de Mariana Echalar. São Paulo: Boitempo, 2016.

FREITAS, L. C. de. Ensino médio: elite atrasada descarta arte e educação física. 22 set. 2016. Disponível em: https://avaliacaoeducacional.wordpress.com/2016/09/22/ ensino-medio-elite-atrasada-descarta-arte-e-educacao-fisica/?iframe=true\&theme preview=true. Acesso em: 18 nov. 2018.

FREITAS, L. C. A reforma empresarial da educação. Nova direita, velhas ideias. São Paulo: Expressão Popular, 2018a.

FREITAS, L. C. de. BNCC é Common Core. 2018b. Disponível em: https:// avaliacaoeducacional.com/2018/01/31/bncc-e-common-core/. Acesso em: 17 nov. 2018.

FRIGOTTO, G. Reforma de ensino médio do (des)governo de turno: decreta-se uma escola para os ricos e outra para os pobres. 23 set. 2016. Disponível em: https:// avaliacaoeducacional.com/2016/09/23/frigotto-segregacao-aprofundada/. Acesso em: 18 nov. 2018.

FUNDAÇÃO ULYSSES GUIMARÃES; MOVIMENTO DEMOCRÁTICO BRASILEIRO (PMDB). Uma ponte para o futuro. Brasília, 2015. Disponível em: https://www.fundacaoulysses.org.br/wp-content/uploads/2016/11/UMA-PONTEPARA-O-FUTURO.pdf. Acesso em: 18 nov. 2018.

INTERNACIONAL DE LA EDUCACIÓN PARA AMÉRICA LATINA (IEAL). Tendencias en educación. Comercio educativo: entramados políticos, económicos e ideológicos para comercializar un derecho. San José: IEAL, 2018. Disponível em: https://ei-ie-al.org/recurso/tendencias-en-educacion-2018. Acesso em: 22 fev. 2019.

MACEDO, E. "A base é a base". E o currículo o que é? In: AGUIAR, M. A. da S.; DOURADO, L. F. (orgs.) A BNCC na contramão do PNE 2014-2024: avaliação e perspectivas. Recife: Anpae, 2018. p. 28-33.

MIGUEL, L. F. Democracia e representação: territórios em disputa. São Paulo: Editora da Unesp, 2014.

RAVITCH, D. Yes, It Is True! I Don't Like School Choice! I Admire Teachers'Unions! Public schools are part of the promise of America. 2017. Disponível em: https://www. huffingtonpost.com/entry/yes-it-is-true-i-dont-like-school-choice-i-admire-teachersunions_us_59de9bc0e4b0eb18af061126?section=us_education. Acesso em:17 nov.2018. RAVITCH, D. New York: Common Core Produces Massive Failure in Writing. 2018. Disponível em: https://nepc.colorado.edu/blog/new-york-common. Acesso em: 17 nov. 2018. 
ROBERTSON, S.; VERGER, A. A origem das parcerias público-privada na governança global da educação. Educação \& Sociedade, Campinas, v. 33, n. 121, p. 1133-1156, out./dez. 2012. http://dx.doi.org/10.1590/S0101-73302012000400012

SANTOS, B. de S. Introdução. In: SANTOS, B. de S. A difícil democracia: reinventar as esquerdas. São Paulo: Boitempo, 2016. p. 13-22.

VALLADARES, M.T. R.; GIRARDI, G.; NOVAES,Í. F. de. Contexto da construção da primeira e segunda versões da Base Nacional Comum Curricular no componente curricular de geografia. Giramundo, Rio de Janeiro, v. 3, n. 6, p. 7-18, jul./dez. 2016.

\section{SOBRE OS AUTORES}

Marilda de Oliveira Costa é doutora em educação pela Universidade Federal do Rio Grande do Sul (UFRGS). Professora da Universidade do Estado de Mato Grosso (UNEMAT).

E-mail: marildacosta532@gmail.com

Leonardo Almeida da Silva é doutor em ciência política pela Universidade Federal Fluminense (UFF). Professor da Universidade do Estado de Mato Grosso (UNEMAT).

E-mail: leonardo_almeidadasilva@yahoo.com.br

Recebido em 11 de março de 2019

Aprovado em 27 de agosto de 2019 